\title{
MUDANÇA DE VERGÍLIO FERREIRA: A GUINADA SUBJETIVA
}

\author{
Madalena Vaz Pinto*
}

Dedico esta apresentação às alunas do grupo de pesquisa sobre Vergílio Ferreira da Faculdade de Formação de Professores, em S. Gonçalo: Letícia Alves, Nathalia Andrade, Nathalia Nunes, Fabiana Decker.

Evolução não parece ser uma boa palavra para falar de projeto literário. Mesmo em um escritor como Vergílio Ferreira em cuja obra é possível assinalar não só modos de escrita distintos como distintas concepçóes teóricas que orientam essa escrita, mesmo assim é preferível, e mais exato, afinal, referirmo-nos a deslocamentos, ajustes, mudanças. Isto já situa a escrita ficcional em um lugar diferente da investigação de caráter pragmático e objetivo onde se abandonam procedimentos por não servirem ao propósito que se pretende alcançar. Mesmo que o escritor faça acompanhar a produção da obra ficcional de escritos sobre essa mesma produçáo, ensaios e diários que são também espaços de reflexão, escrever, ao que parece, não acontece antes, acontece durante, caminho que só se percebe a posteriori.

Sobre os motivos da escrita deste texto: ele se insere na pesquisa que realizo sobre Vergílio Ferreira, orientada pela convicção de que se trata de um autor incontornável para pensar os modos de construção da subjetividade na literatura portuguesa moderna e contemporânea. O motivo de concentrar este comentário em Mudança (1949), quarto romance do autor, deve-se ao fato de ser aquele em que Vergílio Ferreira começa a ensaiar o seu afastamento do neorrealismo, ou seja, de uma literatura orientada a partir de valores ideológicos, em direção a uma literatura sobretudo interessada no valor da liberdade do homem, isto é, existencialista. Dito de outra maneira: onde o autor começa a afastar-se do romance-espetáculo em direção ao romance-ensaio ou romance-problema.

A experiência de ler Vergílio Ferreira é contraditória: reconfortante porque legitima uma temporalidade reflexiva; estranha, porque essa temporalidade parece se constituir à revelia do mundo em que se vive, numa espécie de realidade suspensa, longe dos

\footnotetext{
* Professora Adjunta da Faculdade de Formaçáo de Professores da Universidade do Estado do Rio de Janeiro - FFP-UERJ e Diretora do Centro de Estudos do Real Gabinete Português de Leitura.
} 
efeitos da aceleração da vida e consequentes alteraçóes da percepção. A comprovar esta afirmação, atente-se para o fato do espaço, na maioria dos romances do autor, ser o da aldeia, da vila ou da pequena cidade. Trata-se, portanto, de uma escolha autoral, a reforçar o pacto de leitura que tais textos demandam: um afastamento do mundo objetivo e o assumir de uma atitude predominantemente reflexiva. $\mathrm{O}$ que cabe indagar é se reflexão e ação precisam ser de tal forma apartadas, se a construção de uma subjetividade atenta ao seu processo de pensamento e devir, deve assentar em tais parâmetros.

Mudança, ao contrário do que acontece em grande parte da produçáo posterior de Vergílio Ferreira, não se fez acompanhar de ensaios ou diários a partir dos quais seja possível acompanhar a reflexão que esteve na base de sua construção. $\mathrm{O}$ primeiro dos cinco volumes de Espaço do invisivel (coletânea de ensaios), é publicado em 1965, isto é, dezesseis anos depois da publicação de Mudança; Conta Corrente, série de diários do autor, começa em 1969. À data de publicação do romance, portanto, só o primeiro de seus ensaios, dedicado a um só autor ou problema - Sobre o humorismo em Eça de Queirós (1943) - tinha sido publicado. Esta situação alterou-se em 2008, ano em que foi publicado o Diário Inédito, escrito entre 1944-1949, dos vinte e oito aos trinta e três anos do escritor, e que inclui o período de escrita de Mudança. Cito uma passagem:

\begin{abstract}
Acabei hoje mais um romance. Mudança, lhe chamei eu. Não sei bem se o seu tema interessará. A mim diz-me muito, talvez por ter ainda à sua roda o calor com que o escrevi. Em arrefecendo, verei. Póe-se-me, de facto, como problema agudo, a luta entre realidade fluente e a necessidade de uma regra. Se o homem pretendesse agir em absoluta coerência com a verdade de cada momento, teria de cruzar os braços. Porque em cada instante a vida está negando a verdade que nela descobrimos. (FERREIRA, 2010, p. 140-1). Grifos nossos
\end{abstract}

É possível depreender pelos apontamentos aqui reunidos que desde cedo Vergílio Ferreira lia filosofia, e não só lia como orientava a construçáo dos seus romances a partir de ideias que lhe chegavam via filosofia. O que o Diário não mostra, e Mudança é um bom exemplo disso, são os modos próprios da escrita ficcional, não orientados segundo determinaçôes prévias. Que existe o "saber mais do romance" (MOURÃO, 2001, p. 56). Por outro lado, se no processo da escrita ficcional nunca se sabe bem onde ela vai dar "Isto não significa que não possa haver, por parte do autor, uma intenção global acerca da distribuiçáo dos valores num dado romance, nomeadamente através de personagens mais 'positivas' ou mais 'negativas'" (MOURÃO, 2001, p. 51).

Passemos agora à nossa leitura. Na primeira cena de Mudança assiste-se à descriçáo de um fim de tempestade, em uma vila do norte de Portugal, e à sensação de paz que provoca no protagonista : "Tudo está certo no mundo", "Tudo está no seu lugar." $(M, \text { p.6 })^{1}$ Mas, como a epígrafe do livro anuncia, a partir de um verso de Camóes "Todo mundo é composto de mudança" - a narrativa vai apresentá-la em vários sentidos, sempre em uma relaçáo dialética entre o fora, dos acontecimentos, e seus efeitos

${ }^{1}$ As referências ao romance serão identificadas com a abreviatura $\mathrm{M}$, seguida do número da página. 
no interior do protagonista. A sensaçáo de harmonia experimentada por Carlos Bruno e assente na experiência de proximidade com a natureza, vai repetir-se várias vezes durante o romance e funcionará como uma referência estável, uma espécie de refúgio, em contraste com os acontecimentos que se sucedem ao longo da narrativa: crise do capitalismo mundial em 29, segunda guerra mundial e seus efeitos em Portugal e diretamente na vida de Carlos: falência da fábrica do pai, suicídio deste, saída de Carlos e da mulher da aldeia de Vilarinho, para a cidade de Castanheira. Juntam-se a estes fatos o enriquecimento do pai de Berta - que, entretanto, compra a antiga casa do pai de Carlos e restaura a fábrica de tecelagem que volta a ser lucrativa - e sua consequente ascendência social. Esta alteração tem efeitos na relação de forças do casal e será mais um fator de angústia para Carlos.

Mas, se se reparar bem, a citada harmonia do começo da narrativa já era então percebida por Carlos como sensação rara, incomum, embora essencial: "São-me boas estas horas, esta paz. Boas. Como eu sei. [...] - Tornava-me um dragão, Berta, palavra de honra, se não fossem estas horas de paz, de vez em quando, esta coisa de fora a calcar, a esmagar as forças de dentro." (M, p. 6-7) As "forças de dentro", a que a narrativa tantas vezes fará referência, sinalizam um estado de inquietude quase permanente em Carlos, provocado pela situaçáo política conturbada, mas, sobretudo, por seu modo particular de agir, preocupado com princípios, linhas gerais de orientaçáo que se pretendem permanentes: "Carlos não compreendia a vida sem um domínio pessoal. Porque estar vivo era decifrar o mundo com seus próprios olhos [...]." ( $M$, p.14)

Este embate vai gerar uma atmosfera de conflito entre Carlos e todos os que o rodeiam, inclusive a mulher. A questáo política nunca se lhe colocara. Dada a sua situação privilegiada, de posiçóes sociais definidas, nunca the tinham exigido um posicionamento, nunca tivera necessidade de avaliar seus princípios, sua validade e repercussão, como fica claro em um de seus solilóquios: "Decerto ele tinha uma política, nunca a discutira, como as verdades do senso comum. ( $M$, p. 43)

Carlos defende os valores da consciência, os princípios morais, insiste na correspondência entre o público e o privado, o que o impede de responder às situaçóes que a vida apresenta e à consequente necessidade de sua atualizaçấo destes, na ação: "Carlos, porém, não tinha olhos para fora de si. A guerra paralisava-o, de novo, à roda da força da sua certeza. [...] Mortos, cidades arrasadas, eram tinta de imprensa sem corpo nem voz. Por cima, cruzavam-se as vigas de um mundo definitivo." ( $M$, p. 43) Sua atitude contrasta com a de Pedro, meio irmão, filho bastardo de seu pai, marxista convicto, envolvido na política, que assume atitudes de luta, de ação, convicto de que o absoluto se resolve no relativo:

Toda a verdade, a mais profunda, tratada em termos de catecismo torna-nos logo ridículos, faz de nós bonecos de petulância. Mas acabou-se. Não tenho agora à mão outro modo de falar. Admite, pois, que a História é feita pelas necessidades imediatas. Talvez te sirva. História, claro, não são só guerras. É um pouco mais. Leis, moral, literatura. Cada época, cada necessidade. ( $M$, p. 132) 
Se retomarmos o problema que Vergílio Ferreira pretendia investigar, "luta entre realidade fluente e a necessidade de uma regra." ( $M$, p. 140-141), é agora necessário investigar melhor, perceber os significados desses termos "realidade fluente" e "regra", pois eles podem ser enganadores. Se a realidade fluente é a História, e esta não está determinada pela regra, cabe acentuar que se trata de uma fluência orientada por conceitos ideológicos precisos, neste caso, marxistas e, portanto, não pode ser confundida com uma abertura em busca da melhor forma de agir à medida que os acontecimentos se apresentam. De acordo com a fenomenologia que Vergílio Ferreira já investigava, e mais exatamente da Fenomenologia do espirito, de Hegel, as posiçóes de Carlos e Pedro correspondem a dois posicionamentos: aquele em que o Absoluto se reconcilia consigo mesmo, onde é possível ler o absoluto no relativo, posição de Pedro; e o que vive na perspectiva da consciência infeliz, orientado por princípios rigorosos e imutáveis, como parece ser o caso de Carlos,

Hegel, naturalmente o da Fenomenologia, propunha-me duas soluçóes: uma, que era a dele e a de Marx, era a do panlogismo otimista que se terminava na uniáo do Absoluto consigo mesmo, ou seja, para Marx, num talvez remate da História pelo triunfo do proletariado; outra, a do pantagrismo, que é o caminho doloroso para lá. Naturalmente, escolhi a pior, ou seja, a do pantagrismo - e daí nasceu o meu livro Mudança. (FERREIRA, 1976, p. 13-14).

Para Hegel, a consciência infeliz, isto é, a consciência das contradiçôes, constitui a mola central da fenomenologia. Essa contradição, entretanto, é um estágio passageiro para ir mais longe. A tese gera a sua negaçáo, a antítese, e, por último, a síntese. A síntese firmará uma nova tese a qual, por sua vez, se desenvolverá em uma nova antítese; estas serão superadas em uma nova síntese e assim sucessivamente, de modo a atingir a consciência total do Absoluto consigo mesmo. Mas esta lógica pode ser vista sob a perspectiva náo de um remate ideal, mas sim pelo que implica de doloroso. Isto é: a consciência infeliz e a angústia podem ser entendidas como ponto de passagem ou como parte inerente da vida. Panlogismo e pantagrismo denominam cada uma das atitudes. Pedro vive de acordo com panlogismo otimista, vê o absoluto no relativo; Carlos, ao contrário, é a expressão da consciência infeliz.

$\mathrm{Na}$ narrativa propriamente dita, o conflito entre as duas atitudes manifesta-se pela alternância entre o espaço exterior, em que se desenvolvem as açôes e onde é necessário assumir posiçóes, políticas, principalmente, dado o contexto; e o espaço interno, da consciência, que começa a adquirir um lugar de predominância. Em termos gerais, entretanto, este contraste não é bem resolvido. A atitude de Carlos, que beira a paralisação em muitos momentos, está dubiamente caracterizada. Destaco algumas passagens do texto: "A própria existência do universo decidia-se-lhe na existência de si mesmo. Era homem nos limites do seu tamanho. E 2+2 só eram quatro, depois de ele o saber. Que importavam os outros? "( $M$, p. 72); "Acreditava agora que uma ideia tinha o direito a cerrar a ira de um punho, que a justiça tinha direito à violência. Porque 
a violência, a ira não eram entáo de um homem, da sua pequenez suficiente, mas da sua grandeza, daquilo que o transcendia [...]." ( $M$, p. 72$)$

Trata-se de fato de uma dificuldade de atualizaçấo do pensamento na açáo, ou antes de um 'amuo' de burguês, da impossibilidade de relacionamento (e o problema de casal mostra bem isso) de um sujeito para quem a vida mudou repentinamente, retirando-o de uma posição privilegiada? A ambiguidade que resulta da leitura parece náo funcionar inteiramente como valor, dada esta hesitação na construçáo da personagem, a oscilar entre a crítica e a salvaguarda de uma conduta pautada pelos valores da consciência, mas que tantas vezes se manifesta como impossibilidade de agir. Se existe em Mudança o começo de uma maior valorização da questão da liberdade, o desejo de pensá-la segundo coordenadas mais amplas não exclusivamente determinadas histórica e ideologicamente, poder-se-ia entender a importância da infância em Carlos Bruno como o lugar de restauração de uma 'verdade' intocada pelos acontecimentos da História. Na narrativa, entretanto, a volta de Carlos ao sótáo da antiga casa, soa como um gesto forçado e de efeitos dúbios, uma vez que tal reencontro com uma possível singularidade está a priori negado a Pedro, o filho bastardo, aquele 'sem casa'.

Talvez seja possível pensar que Vergílio Ferreira experimenta neste momento uma hesitação entre a recusa e a valoração de um modo mais "complexo" de pensar a existência, provocando, via ficçáo, furos no edifício concreto neorrealista, para o qual a subjetividade é coletiva e onde a interioridade é vista como luxo burguês. O mais curioso sobre Mudança, entretanto, é que a mudança que aí começa a tomar forma só será percebida pelo autor anos mais tarde. Antes dessa releitura, Mudança é um romance neorrealista, fundado na oposição de duas personagens, Pedro, marxista, personagem de valor positivo; Carlos, hesitante, personagem de valor negativo. É esta disposição, aliás, que explica sua inserção pacífica no neorrealismo. $\mathrm{O}$ fato de não ter sido imediatamente percebida pelo escritor, de náo ter sido intencional, leva obrigatoriamente a modalizar a questấo do romance de tese, a recolocar o problema da orientação prévia do romance a par da força exercida pela autonomia que a escrita ficcional adquire frente a ela. Esta hipótese encontra fundamento em um comentário do autor, anos mais tarde:

Hoje, relendo o livro, eu sint[o] que havia aí um pouco de má-consciência, isto é, o Carlos, apesar do sinal negativo que eu desejaria imprimir-lhe, acabou por ser para mim, quando releio hoje o romance como qualquer leitor, um sinal positivo, não pejorativo. (FERREIRA Apud MOURÃO, 2001, p. 52.) Grifo nosso

Esta releitura implica por sua vez uma outra revisão, aquela da sua adesão ao neorrealismo:

Eu entrei no neorrealismo, ou seja, na arte "social", como quem entra em convento, ou seja pela abdicaçáo. Recordo o meu primeiro livro [O caminho fica longe, 1943] (...) mas a arte de compromisso, engagé, é isso mesmo: o esquecimento de que uma obra de arte é antes de mais uma obra de arte (...) 
Além de que toda a arte está comprometida com o seu tempo; logo, não deve comprometer-se. (FERREIRA, 1976, p.12-13.)

Eduardo Lourenço, na releitura que faz do romance (1968) vai apontar as mudanças de Mudança. Apesar de reconhecer imperfeiçōes na sua construção, "um romance ainda escravo de um passado que ele ajudaria a sepultar." (LOURENÇO, 1969, p. IX.) Lourenço aponta como seu maior valor a instauraçáo da ambiguidade em uma literatura pautada pelos valores da clareza e transparência da linguagem. Tal clareza, é claro, não se pode desvincular de uma concepção de história em direçáo ascendente, rumo à superação e em relação à qual Vergílio Ferreira se distancia: "Não chegou ainda ao mundo o reino da justiça do mundo. Mas que fazer se nem todos descobrem aí um limite?" (FERREIRA, 1990, p. 176-177)

A opção pelo monólogo que vai tomando cada vez mais espaço nos romances de Vergílio e se tornará a sua característica principal, corresponde à tentativa de mostrar os acontecimentos tal como vividos internamente pela personagem, não regidos pelo tempo cronológico. Como se poderá verificar pelos romances que se seguem a Mudança, o narrador assumirá uma posição totalizante, o espaço dos acontecimentos será progressivamente reduzido a par da ampliação de um olhar sobre si, por parte do narrador. Para Eduardo Lourenço, uma diferença começa a operar-se na literatura portuguesa: enquanto no Novo Romance a opçâo pela primeira pessoa correspondia ao questionamento radical do gesto romanesco, Vergílio Ferreira é capaz de manter o mínimo de 'ilusão realista' de modo a não sucumbir à morte do gênero que entấo se anunciava. Mas não só ele, também os desenvoltos filhos de Álvaro de Campos (LOURENÇO, 1993) - Agustina, Almeida Faria, Maria Velho da Costa, Cardoso Pires, entre outros - ao resolver positivamente "aquela espécie de contradição nacional entre o projecto romanesco tal como a grande tradição europeia o configurou e o irresistível pendor subjetivista da nossa literatura."(LOURENÇO, 1969, p. IX-X). Tal análise fez história e mantém-se fundamental na pesquisa sobre formas de construção de subjetividade na literatura portuguesa. Entretanto, não obstante sua pertinência histórica e crítica, ela poderia, aos poucos, começar a ser confrontada com algumas outras - Eduardo Prado Coelho, José Gil - para quem tal singularidade se construiu à custa de uma atitude refratária em relaçáo a linhas de pensamento que alteraram concepçóes de sujeito e de linguagem. Este reposicionamento crítico foge ao escopo deste texto, ficando para outra ocasião.

Resumo: O artigo propóe uma análise do romance Mudança, de Vergílio Ferreira, considerado como aquele em que o autor se afasta do neorrealismo rumo a uma literatura de cunho reflexivo. Sugere-se que tal opçáo aponta para um traço re- corrente na formulaçáo da subjetividade na literatura portuguesa.

Palavras-Chave: Mudança, Literatura Portuguesa, Vergílio Ferreira, subjetividade. 
Abstract: The article is focused in the novel seen as a paradigmatic subjective feature in Mudança, by Vergilio Ferreira, considering Portuguese literature.

it as a turning-point in his work, moving from a neorealistc perspective into a more self-reflexive literature. This change can be

Keywords: Mudança, Portuguese Literature, Vergilio Ferreira, Subjectivity.

\section{REFERÊNCIAS}

FERREIRA, Vergílio. Diário inédito. 2 ed. Edição de Fernanda Irene Fonseca. Lisboa: Quetzal, 2010.

. Espaço do invisivel I. Lisboa: Bertrand, 1990.

. Espaço do invisivel II. Lisboa: Arcádia, 1976. Mudança. 3ed. Lisboa: Portugália, 1969.

LOURENÇO, Eduardo. Acerca de Mudança. In: FERREIRA, Vergílio. Mudança. 3ed. Lisboa: Portugália, 1969.

MOURÃO, Luís. Panlogismo, pantagrismo e o saber mais do romance. Uma leitura de Mudança de Vergílio Ferreira. In: Vergílio Ferreira: excesso, escassez, resto. Braga: Angelus Novus, 2001. 